\title{
Tropical cyclone genesis potential index in climate models
}

\author{
By SUZANA J. CAMARGO ${ }^{1 *}$, ADAM H. SOBEL ${ }^{2}$, ANTHONY G. BARNSTON ${ }^{1}$ and KERRY \\ A. EMANUEL ${ }^{3},{ }^{1}$ International Research Institute for Climate and Society, Lamont Campus, Palisades, NY, USA; \\ ${ }^{2}$ Department of Applied Physics and Applied Mathematics, and Department of Earth and Environmental Sciences, \\ Columbia University, New York, NY, USA $;{ }^{3}$ Program in Atmospheres, Oceans and Climate, Massachusetts Institute of \\ Technology, Cambridge, MA, USA
}

(Manuscript received 30 August 2006; in final form 29 January 2007)

\begin{abstract}
The potential for tropical cyclogenesis in a given ocean basin during its active season has been represented by genesis potential indices, empirically determined functions of large-scale environmental variables which influence tropical cyclone (TC) genesis. Here we examine the ability of some of today's atmospheric climate models, forced with historical observed SST over a multidecadal hindcast period, to reproduce observed values and patterns of one such genesis potential index (GP), as well as whether the GP in a given model is a good predictor of the number of TCs generated by that model. The effect of the horizontal resolution of a climate model on its GP is explored.

The five analysed models are capable of reproducing the observed seasonal phasing of GP in a given region, but most of them them have a higher GP than observed. Each model has its own unique relationship between climatological GP and climatological TC number; a larger climatological GP in one model compared to others does not imply that that model has a larger climatological number of TCs. The differences among the models in the climatology of TC number thus appear to be related primarily to differences in the dynamics of the simulated storms themselves, rather than to differences in the simulated large-scale environment for genesis. The correlation of interannual anomalies in GP and number of TCs in a given basin also differs significantly from one model to the next.

Experiments using the ECHAM5 model at different horizontal resolutions indicate that as resolution increases, model GP also tends to increase. Most of this increase is realized between T42 and T63.
\end{abstract}

\section{Introduction}

Tropical cyclone-like disturbances have long been found in in climate simulations (Manabe et al., 1970; Bengtsson et al., 1982, 1995; Tsutsui and Kasahara, 1996; Vitart et al., 1997, 1999; Camargo and Sobel, 2004). These disturbances have properties qualitatively similar to those of observed tropical cyclones, but due to the low resolution of most simulations (with a few exceptions, e.g. Oouchi et al., 2006; Yoshimura et al., 2006), are much weaker in amplitude and larger in scale than observed tropical cyclones. Despite this deficiency, tropical cyclone (TC) activity has been examined in global climate models for various purposes. One purpose is understanding large-scale climate influences on TCs. This has been explored using low-resolution atmospheric (e.g. Wu and Lau, 1992; Vitart and Anderson, 2001; Camargo

\footnotetext{
*Corresponding author.

e-mail: suzana@iri.columbia.edu

DOI: $10.1111 / \mathrm{j} .1600-0870.2007 .00238 . x$
}

et al., 2005) and coupled atmospheric-ocean models (Matsuura et al., 1999, 2003; Yumoto et al., 2003; Vitart et al., 2003; Vitart, 2006). Given the large difference in space and timescales between TCs and climate variability, computing limitations require compromise of some kind, and this approach, in which deficiencies in the simulation of TCs are accepted in order to allow explicit simultaneous simulation of larger-scale climate variability, has led to useful results.

One issue of particular interest is the skill of global models in forecasting year-to-year variability of seasonal TC activity. While the relatively low resolution of most climate simulations renders them inadequate for forecasting individual cyclones' tracks and intensities, some climate models do have skill in forecasting seasonal TC activity (Bengtsson, 2001). Currently, experimental dynamical seasonal forecasts of TC activity are issued by the International Research Institute for Climate and Society (IRI, 2006) and the European Center for Medium-Range Weather Forecasts (Vitart and Stockdale, 2001; Vitart et al., 2003; Vitart, 2006). The approach used in producing these experimental dynamical forecasts involves detecting and tracking TC-like 
structures in the climate models (atmospheric or coupled atmosphere-ocean models).

Another topic of much recent interest is the possible influence of global climate change on TC activity (Emanuel, 2005a,b; Landsea, 2005; Pielke, 2005; Pielke et al., 2005, 2006; Webster et al., 2005; Anthes et al., 2006; Chan, 2006; Hoyos et al., 2006; Mann and Emanuel, 2006). As climate models are tools of central importance in predictions of climate change, it is natural to use them to investigate the influence of greenhouse gases on TC activity. This has been done in a number of studies, using a variety of approaches (Broccoli and Manabe, 1990; Ryan et al., 1992; Haarsma et al., 1993; Bengtsson et al., 1996; Royer et al., 1998; Druyan et al., 1999; Walsh and Ryan, 2000; Sugi et al., 2002; Knutson and Tuleya, 2004; Walsh et al., 2004; Walsh, 2004; Bengtsson et al., 2006). An approach that has been used in some studies (e.g Bengtsson et al., 1996; Sugi et al., 2002) involves identifying and tracking the models' TC-like vortices, and asking how their numbers and intensities change over time as the larger-scale climate does. Due to the relatively poor representation of TC dynamics in low-resolution climate models, results from this approach can be provocative, but not entirely convincing. As yet there have been very few global simulations using high-resolution models that simulate realistic TCs (Chauvin et al., 2006; Oouchi et al., 2006; Yoshimura et al. 2006).

Another approach to analysing the relationship between TCs and climate, for the purpose of forecasting both seasonal to interannual variations and long term changes, involves analysing simulated variations in the large-scale environment, focusing on those large-scale variables known to affect TC activity (Ryan et al., 1992; Watterson et al., 1995; Thorncroft and Pytharoulis, 2001). The strength of this approach is that the ability of climate models to simulate the large-scale climate, while somewhat flawed, is clearly superior to their ability to simulate TCs. This approach thus plays to the strength of the models. A complication is that a choice has to be made regarding which variables, or combinations of variables, should be analysed, and how the results should be interpreted, given that our understanding of the mechanisms by which the large-scale environment influences TC activity is limited. Recent studies (McDonald et al., 2005; Chauvin et al., 2006) have compared both approaches, both tracking model TCs and analysing genesis parameters in the same model in simulations of both current and future climate.

We focus here on climate models' simulations of factors influencing the number of TCs that occur in a given basin in a given year. This number is governed by the process of tropical cyclogenesis. While much is known about which factors influence genesis, a quantitative theory (such as exists at least in part for intensity, as described in Emanuel, 1995), is lacking. In the absence of such a theory, empirical methods are useful. Gray (1979) developed an index which was able to replicate key features of the seasonal and spatial variability of observed genesis using a handful of environmental parameters. In this study, we use an empirical genesis potential index (GP), broadly similar to that of Gray, to quantify the proclivity of the large-scale environment to TC genesis.

We examine both the environment for TC activity, as well as the simulated TC activity itself, in five different atmospheric climate models. We wish to ascertain both how well the models simulate the climatological environment for TC genesis (as represented by the genesis potential index), compared to that found in a reanalysis data set, as well as whether the statistics of the simulated TC-like disturbances bear relationships to their simulated environments similar to those between real TCs and theirs. Evaluating the ability of current climate models to reproduce the genesis potential index is a first step towards analysing the models' performance in future climate scenarios as well as the representativeness of the genesis potential index in forecasting the interannual variability of seasonal TC activity.

In Section 2, we describe the genesis potential index, and the models, the data and methodology used in this study. In Section 3, the genesis potential index climatology in the models is discussed, and in Section 4 the TC activity in the models is analysed and compared with the genesis potential index characteristics. The influence of horizontal resolution is discussed in Section 5. A discussion and some conclusions are given in Section 6.

\section{Methodology}

The genesis potential index (GP) that we use was developed by Emanuel and Nolan (2004), motivated by the work of Gray (1979), and has been used by Nolan et al. (2006) and Camargo et al. (2006, 2007a). We compare the climatological GP, as simulated by the five models, to their simulated TC activity. The latter is obtained by detecting and tracking cyclone-like structures in the model as described by Camargo and Zebiak (2002). A statistical analysis of various aspects of TC activity in three of these models was described in Camargo et al. (2005). The influence of horizontal resolution on the GP will also be explored, by examining a single one of the models run at five different horizontal resolutions.

The GP takes a set of environmental variables that, on physical grounds, reasonably might be expected to be important predictors of tropical cyclogenesis, and combines them into a single number, whose functional dependence on each variable is chosen to capture the spatial and temporal patterns of the genesis climatology and interannual variability in the observed record. In using the selected environmental variables, we avoid features that might be specific to the present climate, such as categorizations based on fixed thresholds, as is the case of the sea surface temperature (SST) in Gray's index. Various studies (Ryan et al., 1992; Royer et al., 1998; McDonald et al., 2005) have shown that due to the dependence on an SST threshold whose value is fixed at a value appropriate to the present climate, the Gray index is not appropriate for future climate scenario studies The set of chosen predictors in the GP used here includes the poten- 
tial intensity (Emanuel, 1986), relative humidity and absolute vorticity at various levels, and vertical wind shear. The vertical wind shear is defined as the magnitude of the vector difference between the horizontal winds at 850 and $200 \mathrm{hPa}$, as is often used in empirical studies of TC genesis and intensity change.

Emanuel and Nolan (2004) used monthly reanalysis data to relate the spatial and temporal variability of genesis to a limited number of environmental predictors. Monthly average values of each of the predictors were then tested individually and in combination for their ability to replicate the annual cycle of tropical cyclogenesis rates in each hemisphere, as well as for their ability to replicate the spatial distribution of genesis in each month of the year. More details on the GP index can be found in Camargo et al. (2007a). The GP index is defined as

$G P=\left|10^{5} \eta\right|^{3 / 2}\left(\frac{\mathcal{H}}{50}\right)^{3}\left(\frac{V_{\text {pot }}}{70}\right)^{3}\left(1+0.1 V_{\text {shear }}\right)^{-2}$,

where $\eta$ is the absolute vorticity at $850 \mathrm{hPa}$ in $\mathrm{s}^{-1}, \mathcal{H}$ is the relative humidity at $700 \mathrm{hPa}$ in percent, $V_{\text {pot }}$ is the potential intensity in $\mathrm{m} \mathrm{s}^{-1}$, and $V$ shear is the magnitude of the vertical wind shear between 850 and $200 \mathrm{hPa}$ in $\mathrm{m} \mathrm{s}^{-1}$.

The technique used to compute potential intensity, $V_{\mathrm{pot}}$, is a generalization of that described in Emanuel (1995) to take into account dissipative heating (Bister and Emanuel, 1998), in addition to SST, sea level pressure (SLP), and atmospheric temperature and mixing ratio at various pressure levels. The climatological, or low-frequency, variability of the potential intensity was presented in Bister and Emanuel (2002a,b), Bister and Emanuel (2002b). A short definition of the potential intensity can be found in Appendix A.

Although the GP was developed by a statistical fitting procedure based only on the seasonal cycle and spatial variation of the mean genesis climatology of the reanalysis, composite anomalies of the GP for El Niño and La Niña years reproduce interannual variations in the observed frequency and location of genesis with some skill for several basins (Camargo et al., 2007a). This independent test shows that the index has some utility for understanding the influence of climate variations on TC activity.

To define and track TCs in the models, we use an objective algorithm (Camargo and Zebiak, 2002) based in large part on prior studies (Bengtsson et al., 1995; Vitart et al., 1997). The algorithm has two parts. In the detection part, storms that meet environmental and duration criteria are identified. A model TC is identified when chosen dynamical and thermodynamical variables exceed thresholds based on observed tropical storm climatology. Most studies (Bengtsson et al., 1982; Vitart et al., 1997) use a single set of threshold criteria globally; however, these do not take into account model biases and deficiencies. We use basin- and model-dependent threshold criteria, based on each model's own climatology (Camargo and Zebiak, 2002). The second part is the tracking, in which the tracks are obtained from the vorticity centroid, defining the center of the TC using relaxed criteria. The detection and tracking algorithms have been previously applied to regional climate models (Landman et al., 2005; Camargo et al., 2007b) and to several global climate models (Camargo and Zebiak, 2002; Camargo et al., 2005). The dynamics of modelTC formation over the western North Pacific have also been explored using this tracking algorithm (Camargo and Sobel, 2004).

The models used in our analysis are three versions of the European Community-Hamburg models (ECHAM3.6, ECHAM4.5 and ECHAM5), the National Center for Atmospheric Research (NCAR) Community Climate Model 3.6 (CCM3.6), and the NASA Seasonal to Interannual Prediction Project (NSIPP) atmospheric model. The first three models were developed at the MaxPlanck Institute for Meteorology, Hamburg, Germany (Model User Support Group, 1992; Roeckner et al., 1996, 2003), the fourth model at NCAR, Boulder, Colorado (Kiehl et al., 1998) and the last one at NASA/Goddard in Maryland, USA (Suarez and Takacs, 1995). All models were forced with observed SSTs. The model simulations performed at IRI (ECHAM3.6, ECHAM4.5 and CCM3.6) were forced with the Reynolds SST dataset (Reynolds and Smith, 1994; Reynolds et al., 2002), as were the NSIPP simulations while the ECHAM5 was forced with the AMIP2 SST (AMIP II (Atmospheric Model Intercomparison Project II), 2007). The NSIPP and ECHAM5 simulations were performed by their developing institutions. Output from these models is currently available at IRI. The model resolutions, time periods of the simulations, and number of ensemble members vary, as given in Table 1.

Here, the GP of the five climate models and of the National Center for Environmental Prediction/National Center for Environmental Research (NCEP/NCAR) Reanalysis (Kalnay et al., 1996) is calculated using monthly mean data. The TCs in the models are also identified and tracked using either six-hourly or daily data output from the models, depending on data availability.

The observed TC statistics are computed from the best-track datasets developed by the National Hurricane Center (for Atlantic and eastern Pacific) and Joint Typhoon Warning Center (for western North Pacific and southern Hemisphere) (JTWC, 2007; NHC, 2007). From the observed data sets, only TCs with tropical storm or hurricane/typhoon intensity are considered here, that is, tropical depressions are not included.

\section{Genesis potential index model climatology}

In Fig. 1 the annual maximum of the monthly GP climatology at each grid point is shown for the models and the reanalysis. All models capture the well known TC regions, appearing as maxima of the GP. With the exception of ECHAM3 (Fig. 1a), and to a lesser extent CCM3 (Fig. 1b) all models have considerably higher values of the GP than those in the reanalysis. Consequently, the regions conducive to TC genesis are much larger than those in observations in the majority of the models. Because genesis in the models may bear a quantitatively 
Table 1. Simulation properties of the models, including simulation period, horizontal (hor.) and vertical (vert.) resolutions, model type, number of ensemble members (ens.) and output type. ECHAM4 and NSIPP have different periods for the genesis potential (GP) and model tropical cyclones (TCs) analysis

\begin{tabular}{lcccccc}
\hline Model & Years & Hor. Res. & Vert. Res. & Type & Ens. & Output type \\
\hline ECHAM3 & $1950-2000$ & T42 & L19 & spectral & 10 & 6 hourly, monthly \\
ECHAM4 (GP) & $1950-2004$ & T42 & L19 & spectral & 24 & monthly \\
ECHAM4 (TCs) & $1950-2002$ & T42 & L19 & spectral & 24 & 6 hourly \\
ECHAM5 & $1978-1999$ & T42 & L19, L31 & spectral & 2 & 6 hourly, monthly \\
ECHAM5 & $1978-1999$ & T63 & L19, L31 & spectral & 5 & 6 hourly, monthly \\
ECHAM5 & $1978-1999$ & T85 & L19, L31 & spectral & 2 & 6 hourly, monthly \\
ECHAM5 & $1978-1999$ & T106 & L19, L31 & spectral & 2 & 6 hourly, monthly \\
ECHAM5 & $1978-1999$ & T159 & L31 & spectral & 1 & 6 hourly, monthly \\
CCM & $1950-2001$ & T42 & L19 & spectral & 24 & Daily, monthly \\
NSIPP (GP) & $1950-2004$ & $2.5^{\circ} \times 2^{\circ}$ & L34 & grid point & 9 & Monthly \\
NSIPP (TCs) & $1961-2000$ & $2.5^{\circ} \times 2^{\circ}$ & L34 & grid point & 9 & Daily \\
\hline
\end{tabular}

Fig. 1. Annual maximum of monthly genesis potential index in the period 1961-2000: (a) ECHAM3, (b) CCM3, (c) ECHAM4, (d) NSIPP, (e) ECHAM5 (for 1978-1999, resolution T42), (f) NCEP reanalysis.
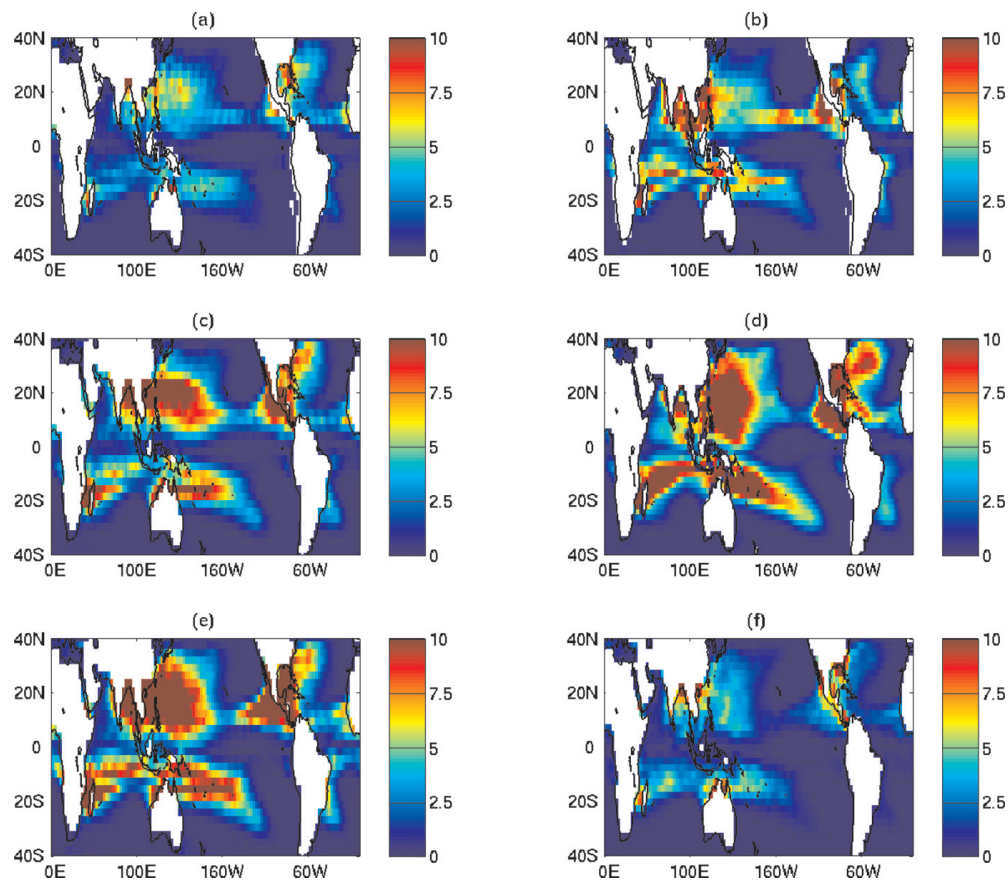

different relationship to the GP than that in observations, this does not necessarily mean that genesis will actually occur more frequently or over a larger area in a given model than it does in observations.

The ECHAM4, ECHAM5 and NSIPP models have large values for the GP in the western North Pacific, while the highest values in the Atlantic occur in the NSIPP model. ECHAM4, ECHAM5 and NSIPP are also the models having highest GP values in the Southern Hemisphere. All models reproduce the seasonal movement of the regions of large GP from the Northern to the Southern Hemisphere (not shown).

We would like to identify which factors are contributing to the high values of GP in most models. To do that, we calculated the relative error, defined as the difference of the model climatology and the reanalysis climatology normalized by the magnitude of the reanalysis climatology at each grid point for the four component variables of the GP. The average of this normalized difference over the western North Pacific for the four variables for all models in ASO is shown in Fig. $2 .{ }^{1}$ The models have a positive bias in the western North Pacific in the relative humidity, with the exception of CCM3, which also has a smaller positive bias in GP than all the other models except ECHAM3. In the case of the ECHAM3, the positive relative humidity bias

\footnotetext{
${ }^{1}$ In this figure, the western North Pacific basin is defined slightly differently than in the rest of the paper, as $135^{\circ}-180^{\circ} \mathrm{E}, 0^{\circ}-30^{\circ} \mathrm{N}$. This was done in order to exclude highly anomalous values along the coastlines of the Philippines and Japan in one model.
} 


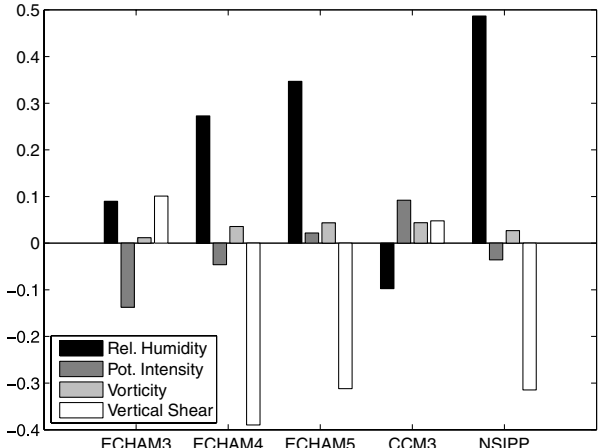

Fig. 2. Average relative error of relative humidity, potential intensity, absolute vorticity, vertical wind shear in the western North Pacific for ASO. In the case of the vertical wind shear, the negative of the error is plotted, reflecting the appropriate sign of the functional dependence of variations in the GP on those in shear. The relative error is defined as the difference of the model climatology and the reanalysis climatology at each grid point normalized by the magnitude of the reanalysis climatology at that grid point.

is balanced by a negative bias in the potential intensity. The GP index is proportional to the cube of both the relative humidity and the potential intensity (see eq. 1). The ECHAM4, ECHAM5 and NSIPP models have a positive vertical shear bias. The GP is inversely proportional to the square of the vertical shear, a lower exponent than that applied to the relative humidity, so it is perhaps not surprising that while the two biases are of cancelling signs, the bias in the relative humidity dominates that in shear. The model GP biases are model and region dependent, as can be seen in Fig. 3 for the arbitrary but typical example of ECHAM4 for the four variables. In that model, the dominant biases occur in the relative humidity and vertical wind shear.
The annual cycle of the mean GP in four regions is shown in Fig. 4. The definitions of the basins, subbasins and their peak seasons are given in Table 2 . The models realistically simulate the basic timing of the TC activity in all four regions, although the month of the maximum does not always coincide with that of the observations. This is particularly true in the case of the North Indian Ocean, where there are two TC subseasons: pre- (AMJ) and post-(OND) Indian monsoon. Most models do capture this feature at least qualitatively, though the first peak occurs too early in the NSIPP model and is nearly entirely missed by the CCM3. In most cases, the relative magnitudes of the GP in each model and in the reanalysis are ordered consistently in each basin, with, the reanalysis, ECHAM3 and CCM tending to have the smallest GP and the NSIPP and ECHAM5 the largest. There are exceptions to this, such as the second peak in the North Indian basin which is stronger in CCM than in NSIPP.

Table 3 shows, individually by basin, the interannual correlation between the seasonal GP in the models and in the reanalysis for the peak season. Significant correlations occur in the Australian, western and eastern North Pacific, and Atlantic regions, for most models. In these regions and seasons, some of these same models had been found to have skill in simulating TC activity (see tables 6 and 7 in Camargo et al., 2005). However, some models that have minimally significant model versus reanalysis GP correlations for the North Indian Ocean, were found to have low simulation skill in model TC activity Camargo et al. (2004, 2005). Conversely, in the South Pacific region, where most models were found to have skill in simulating TC activity, significant model versus reanalysis seasonal GP correlations are absent.

By considering smaller regions or subbasins (defined in Table 2), the correlations of the GP in the models and reanalysis

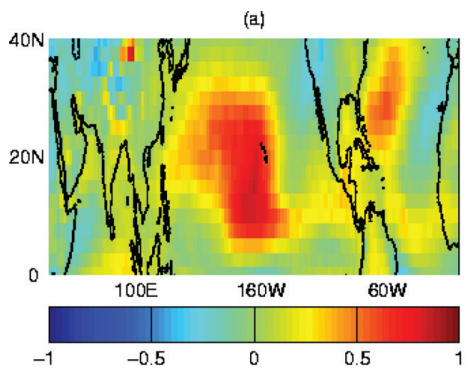

(c)

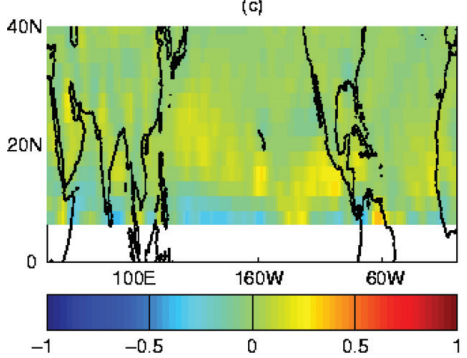

(b)

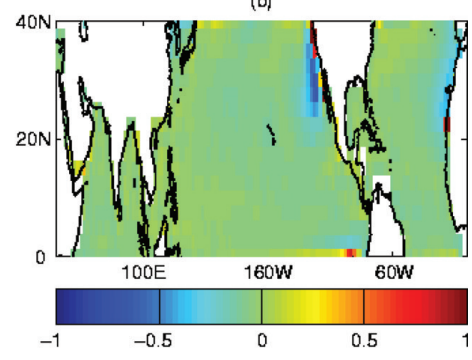

(d)

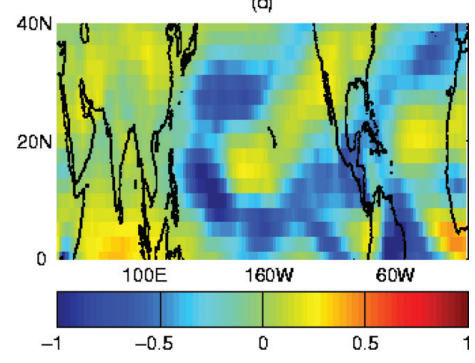

Fig. 3. Relative error of (a) relative humidity, (b) potential intensity, (c) absolute vorticity, (d) vertical wind shear for the ECHAM4 model in ASO. As in fig. 2, the negative of the vertical wind shear error is plotted. The relative error is defined as the difference of the model climatology and the reanalysis climatology at each grid point normalized by the magnitude of the reanalysis climatology at that grid point. The vorticity error is not shown near the equator; the vorticity has very small values in that region, leading to relative errors so large as to dominate the image, while at the same time the region is relatively unimportant for TC genesis. 
Fig. 4. Annual cycle of mean genesis potential index in the models and reanalysis in the (a) Western North Pacific, (b) North Atlantic, (c) North Indian and (d) South Indian basins, in the period 1950-2004, with the exception the ECHAM5 model (for 1978-1999, resolution T42).
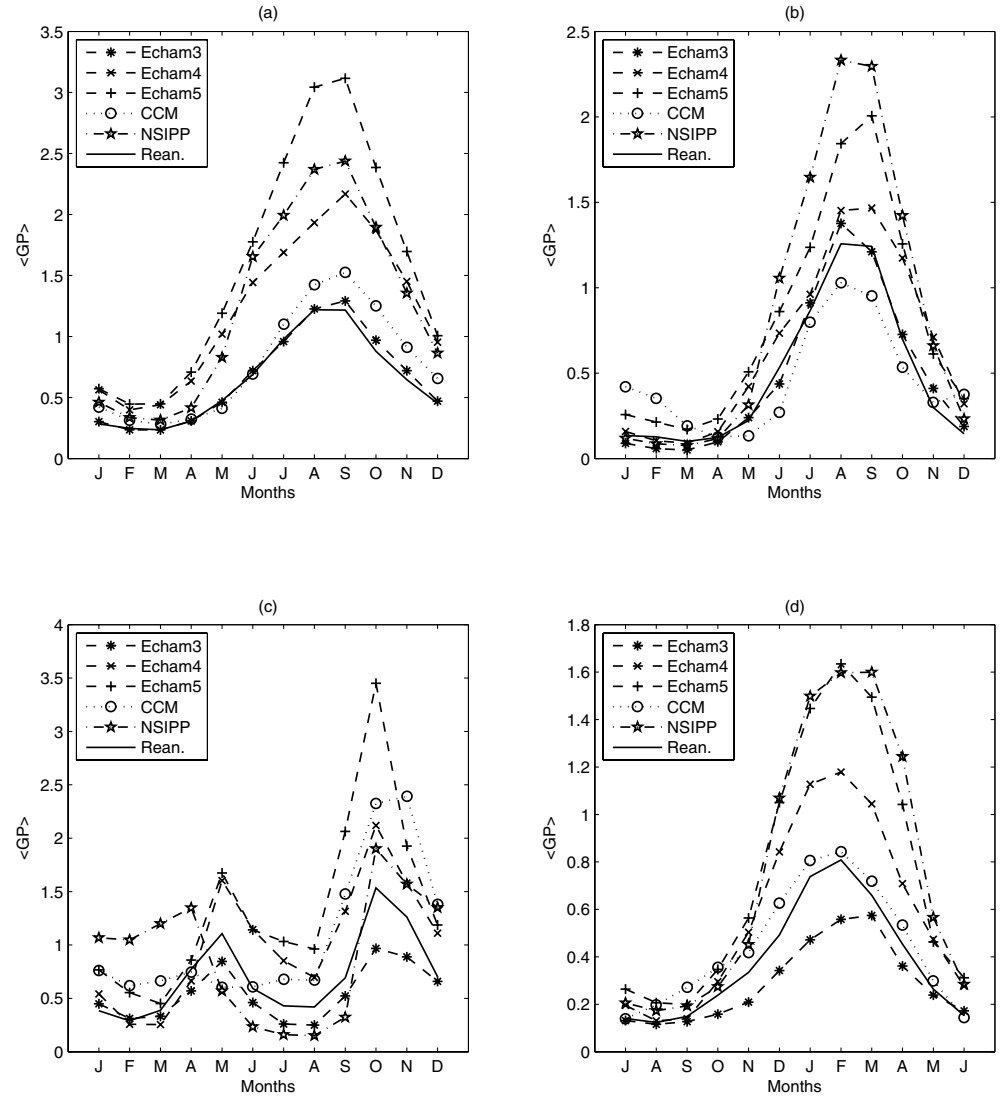

increase noticeably in many subbasins (Table 4). The subbasins were defined based loosely on the positive and negative lobes of the difference of warm and cold ENSO anomalies of the GP for the reanalysis, as shown in figs. $6 \mathrm{c}$ and $8 \mathrm{c}$ of Camargo et al. (2007a) for ASO (Northern Hemisphere) and JFM (Southern Hemisphere), respectively. [ENSO difference composites for an atmospheric general circulation model and genesis potential index different than (but presumably comparable to) those used here are shown in fig. 13b of McDonald et al. (2005).] These subbasins were defined to highlight the interannual genesis variations in regions where those variations are manifest as shifts in the mean genesis location rather than changes in TC number in the basins as wholes, such as the western North Pacific. In warm (cold) ENSO (El Niño-Southern Oscillation) events the mean TC genesis location shifts to the southeast (northwest) (Wang and Chan, 2002), but changes in total basin genesis are minimal (Camargo and Sobel, 2005). There is no significant signal in the GP for the whole basin, as the increase in one part of the basin is compensated by a decrease in the another part. For two smaller regions, whose boundary takes into account the typical shifts in mean genesis location, the mean GP in each subbasin has a stronger interannual signal and the interannual correlations between GP and TC number are larger.

\section{Model TC activity climatology}

Figure 5 shows the climatological annual total track density for the models and observations. The track density is obtained by counting the number of six-hourly track positions of the TCs per $4^{\circ}$ latitude and longitude per year. In the case of the models, the ensemble mean is used. In the case of models with only daily output (CCM and NSIPP) the track density is multiplied by 4 for consistency.

The models' TC activity occurs in approximately the same locations as in observations (Fig. 5f), with model track density patterns differing somewhat from those of the observations and from one another. For instance, all models have too much nearequatorial TC activity. This characteristic may be a result of the models' low resolutions and is common to all the low horizontal resolution models examined here, although it is not present in some other models (e.g. Vitart et al., 1997). Various issues could cause the TC activity to 'leak' into an area that should have no TCs: (i) the model storms are too large and sometimes lack a highly localized maximum in vorticity, leading to errors in the tracking algorithm's placement of the storm centre; (ii) the tracking algorithm's relaxed threshold definition; (iii) differences in observational and model genesis definitions and (iv) the models may actually have a positive bias in the near-equatorial region. 
Table 2. Definitions of the basins and subbasins used in this study, as well as their peak seasons (JFM: January-March, DJF: December-February, OND: October-December, JASO: July-October, JAS: July-September and ASO: August-October) and acronyms

\begin{tabular}{|c|c|c|c|c|}
\hline Region & Acronym & Latitudes & Longitudes & Peak season \\
\hline South Indian & SI & $40^{\circ} \mathrm{S}-0^{\circ}$ & $30^{\circ} \mathrm{E}-100^{\circ} \mathrm{E}$ & JFM \\
\hline S. Indian South & SI S & $40^{\circ} \mathrm{S}-10^{\circ} \mathrm{S}$ & $30^{\circ} \mathrm{E}-100^{\circ} \mathrm{E}$ & JFM \\
\hline S. Indian North & SI N & $10^{\circ} \mathrm{S}-0^{\circ}$ & $30^{\circ} \mathrm{E}-100^{\circ} \mathrm{E}$ & JFM \\
\hline Australian & AUS & $40^{\circ} \mathrm{S}-0^{\circ}$ & $100^{\circ} \mathrm{E}-180^{\circ}$ & JFM \\
\hline Australian South & AUS S & $40^{\circ} \mathrm{S}-10^{\circ} \mathrm{S}$ & $100^{\circ} \mathrm{E}-180^{\circ}$ & JFM \\
\hline Australian North & AUS N & $10^{\circ} \mathrm{S}-0^{\circ}$ & $100^{\circ} \mathrm{E}-180^{\circ}$ & JFM \\
\hline South Pacific & SP & $40^{\circ} \mathrm{S}-0^{\circ}$ & $180^{\circ}-110^{\circ} \mathrm{W}$ & DJF \\
\hline S. Pacific South & SP S & $40^{\circ} \mathrm{S}-10^{\circ} \mathrm{S}$ & $180^{\circ}-110^{\circ} \mathrm{W}$ & DJF \\
\hline S. Pacific North & SP N & $10^{\circ} \mathrm{S}-0^{\circ}$ & $180^{\circ}-110^{\circ} \mathrm{W}$ & DJF \\
\hline North Indian & NI & $0^{\circ}-30^{\circ} \mathrm{N}$ & $40^{\circ} \mathrm{E}-100^{\circ} \mathrm{E}$ & OND \\
\hline North Indian West & NI W & $0^{\circ}-30^{\circ} \mathrm{N}$ & $40^{\circ} \mathrm{E}-77^{\circ} \mathrm{E}$ & OND \\
\hline North Indian East & NI E & $0^{\circ}-30^{\circ} \mathrm{N}$ & $77^{\circ} \mathrm{E}-100^{\circ} \mathrm{E}$ & OND \\
\hline Western North Pacific & WNP & $0^{\circ}-40^{\circ} \mathrm{N}$ & $100^{\circ} \mathrm{E}-165^{\circ} \mathrm{W}$ & JASO \\
\hline W. North Pacific East & WNP E & $0^{\circ}-40^{\circ} \mathrm{N}$ & $100^{\circ} \mathrm{E}-135^{\circ} \mathrm{E}$ & JASO \\
\hline W. North Pacific West & WNP W & $0^{\circ}-40^{\circ} \mathrm{N}$ & $135^{\circ} \mathrm{E}-165^{\circ} \mathrm{W}$ & JASO \\
\hline Eastern North Pacific & ENP & $0^{\circ}-40^{\circ} \mathrm{N}$ & $135^{\circ} \mathrm{E}$ to American coast & JAS \\
\hline North Atlantic & ATL & $0^{\circ}-40^{\circ} \mathrm{N}$ & American to African coast & ASO \\
\hline N. Atlantic West & ATL W & $0^{\circ}-25^{\circ} \mathrm{N}$ & American coast to $30^{\circ} \mathrm{W}$ & ASO \\
\hline N. Atlantic East & ATLE & $0^{\circ}-25^{\circ} \mathrm{N}$ & $30^{\circ} \mathrm{W}$ to African coast & ASO \\
\hline
\end{tabular}

Table 3. Interannual correlations of the seasonal mean GP, per basin (as defined in Table 2), between the models and the reanalysis for the peak TC season for the period 1950-2000 (ECHAM3), 1950-2004 (ECHAM4 and NSIPP), 1978-1999 (ECHAM5) and 1950-2001 (CCM). Bold entries indicate correlation values that have significance at the $95 \%$ confidence level

\begin{tabular}{lcccccccc}
\hline Model & Resol & SI & AUS & SP & NI & WNP & ENP & ATL \\
\hline CCM & T42 & -0.19 & $\mathbf{0 . 5 1}$ & -0.10 & $\mathbf{0 . 2 8}$ & -0.13 & $\mathbf{0 . 5 7}$ & $\mathbf{0 . 5 8}$ \\
NSIPP & $2.5^{\circ}$ & -0.31 & 0.19 & 0.04 & $\mathbf{0 . 2 8}$ & $\mathbf{0 . 2 9}$ & $\mathbf{0 . 6 0}$ & $\mathbf{0 . 3 8}$ \\
ECHAM3 & T42 & 0.08 & $\mathbf{0 . 3 7}$ & 0.20 & $\mathbf{0 . 3 5}$ & $\mathbf{0 . 4 5}$ & $\mathbf{0 . 4 1}$ & $\mathbf{0 . 5 9}$ \\
ECHAM4 & T42 & 0.05 & $\mathbf{0 . 4 9}$ & 0.21 & 0.20 & 0.21 & $\mathbf{0 . 4 4}$ & $\mathbf{0 . 7 4}$ \\
ECHAM5 & T42 & -0.04 & 0.30 & 0.03 & -0.09 & $\mathbf{0 . 4 6}$ & $\mathbf{0 . 5 2}$ & $\mathbf{0 . 4 8}$ \\
ECHAM5 & T63 & 0.02 & $\mathbf{0 . 5 0}$ & 0.03 & 0.31 & $\mathbf{0 . 5 0}$ & 0.37 & 0.41 \\
ECHAM5 & T85 & -0.02 & 0.34 & -0.01 & 0.41 & $\mathbf{0 . 5 2}$ & 0.38 & $\mathbf{0 . 5 2}$ \\
ECHAM5 & T106 & 0.08 & 0.41 & 0.01 & 0.34 & 0.33 & $\mathbf{0 . 5 8}$ & 0.37 \\
ECHAM5 & T159 & 0.10 & $\mathbf{0 . 4 8}$ & 0.33 & $\mathbf{0 . 6 4}$ & 0.27 & 0.35 & 0.37 \\
\hline
\end{tabular}

The tracking threshold was defined in order to avoid definining a new storm in cases when the model storms weakens and subsequently strenghtens again, avoiding an artificial increase of the number of storms (Camargo and Zebiak, 2002; McDonald et al., 2005; Chauvin et al., 2006). This could lead to a model storm definition that would correspond to a pre-genesis stage in the observations.

NSIPP (Fig. 5d) has little TC activity in the eastern Pacific and the North Atlantic. In observations, the track density has two strong maxima in the Northern Hemisphere: one in the eastern and one in the western North Pacific. The models that most clearly reproduce these maxima are ECHAM4 and ECHAM5. In the Southern Hemisphere the track density maximum in the observations lies along a zonal band about $15^{\circ} \mathrm{S}$. In most models, the pattern in the Southern Hemisphere is less zonal, having a more oblique orientation in the southern Indian and southern Pacific Oceans, similar to the south Pacific convergence zone in the latter case.

In general, the models analysed have too few model TCs in each basin, compared to observations. A detailed analysis of the tropical cyclone activity in three of the models models is given in Camargo et al. (2005). The lifetimes of the model storms also tend to be too long (Camargo et al., 2005). In contrast, the Met Office model has a bias of too many model tropical storms and short lifetimes (McDonald et al., 2005). This bias could possibly be attributed to the tracking technique used (Hodges, 1994), which could be splitting the individual model tracks into two shorter tracks and hence increasing the number of storms formed (McDonald et al., 2005). In the tracking technique used here, 
Table 4. Interannual correlations of the seasonal mean GP, per subbasin (as defined in Table 2), between the models and the reanalysis for the peak TC season for the period 1950-2000 (ECHAM3), 1950-2004 (ECHAM4 and NSIPP), 1978-1999 (ECHAM5) and 1950-2001 (CCM). Bold entries indicate correlation values that have significance at the 95\% confidence level

\begin{tabular}{lccccccc}
\hline Model & Resol & SI S & SI N & AUS S & AUS N & SP S & SP N \\
\hline CCM & T42 & -0.02 & $\mathbf{0 . 3 6}$ & $\mathbf{0 . 6 7}$ & $\mathbf{0 . 3 4}$ & $\mathbf{0 . 2 9}$ & $\mathbf{0 . 7 4}$ \\
NSIPP & $2.5^{\circ}$ & -0.20 & $\mathbf{0 . 3 3}$ & $\mathbf{0 . 5 5}$ & $\mathbf{0 . 3 5}$ & $\mathbf{0 . 3 7}$ & $\mathbf{0 . 7 5}$ \\
ECHAM3 & T42 & 0.23 & 0.11 & $\mathbf{0 . 5 8}$ & 0.27 & $\mathbf{0 . 4 6}$ & $\mathbf{0 . 7 8}$ \\
ECHAM4 & T42 & 0.18 & $\mathbf{0 . 3 4}$ & $\mathbf{0 . 6 5}$ & $\mathbf{0 . 3 6}$ & $\mathbf{0 . 4 7}$ & $\mathbf{0 . 8 5}$ \\
ECHAM5 & T42 & -0.16 & $\mathbf{0 . 5 7}$ & 0.42 & 0.40 & 0.42 & $\mathbf{0 . 9 2}$ \\
ECHAM5 & T63 & -0.19 & $\mathbf{0 . 4 9}$ & $\mathbf{0 . 6 2}$ & $\mathbf{0 . 6 0}$ & $\mathbf{0 . 4 5}$ & $\mathbf{0 . 9 1}$ \\
ECHAM5 & T85 & -0.20 & 0.16 & $\mathbf{0 . 5 1}$ & 0.19 & 0.39 & $\mathbf{0 . 9 3}$ \\
ECHAM5 & T106 & -0.05 & 0.38 & $\mathbf{0 . 6 1}$ & $\mathbf{0 . 5 2}$ & 0.40 & $\mathbf{0 . 8 9}$ \\
ECHAM5 & T159 & -0.03 & $\mathbf{0 . 4 8}$ & $\mathbf{0 . 6 4}$ & $\mathbf{0 . 4 7}$ & $\mathbf{0 . 5 0}$ & $\mathbf{0 . 9 3}$ \\
& & & & & & & \\
Model & Resol & NI W & NI E & WNP W & WNP E & ATL W & ATL E \\
& & & & & & $\mathbf{0 . 5 5}$ & -0.08 \\
CCM & T42 & $\mathbf{0 . 5 0}$ & 0.03 & -0.19 & $\mathbf{0 . 5 0}$ & $\mathbf{0 . 7 5}$ & -0.15 \\
NSIPP & 2.5 & $\mathbf{0 . 2 9}$ & 0.20 & $\mathbf{0 . 5 1}$ & $\mathbf{0 . 6 3}$ & $\mathbf{0 . 4 8}$ & -0.08 \\
ECHAM3 & T42 & $\mathbf{0 . 5 8}$ & 0.19 & $\mathbf{0 . 6 3}$ & $\mathbf{0 . 6 4}$ & $\mathbf{0 . 6 7}$ & -0.07 \\
ECHAM4 & T42 & $\mathbf{0 . 3 8}$ & 0.18 & $\mathbf{0 . 5 4}$ & $\mathbf{0 . 5 9}$ & $\mathbf{0 . 7 9}$ & 0.12 \\
ECHAM5 & T42 & 0.04 & -0.07 & $\mathbf{0 . 7 3}$ & $\mathbf{0 . 7 1}$ & $\mathbf{0 . 6 6}$ & 0.01 \\
ECHAM5 & T63 & 0.36 & 0.24 & $\mathbf{0 . 7 3}$ & $\mathbf{0 . 6 9}$ & $\mathbf{0 . 6 3}$ & 0.07 \\
ECHAM5 & T85 & 0.36 & 0.15 & $\mathbf{0 . 7 4}$ & $\mathbf{0 . 6 7}$ & $\mathbf{0 . 6 5}$ & 0.23 \\
ECHAM5 & T106 & 0.08 & 0.40 & $\mathbf{0 . 6 7}$ & $\mathbf{0 . 5 2}$ & $\mathbf{0 . 5 4}$ & $\mathbf{0 . 5 5}$ \\
ECHAM5 & T159 & $\mathbf{0 . 4 8}$ & $\mathbf{0 . 4 6}$ & $\mathbf{0 . 4 5}$ & $\mathbf{0 . 7 1}$ & $\mathbf{0 . 5 3}$ \\
\hline
\end{tabular}

Fig. 5. Track density climatological annual total in the period 1961-2000: (a) ECHAM3, (b) CCM3, (c) ECHAM4, (d) NSIPP, (e) ECHAM5 (for 1978-1999, resolution T42), (f) observations
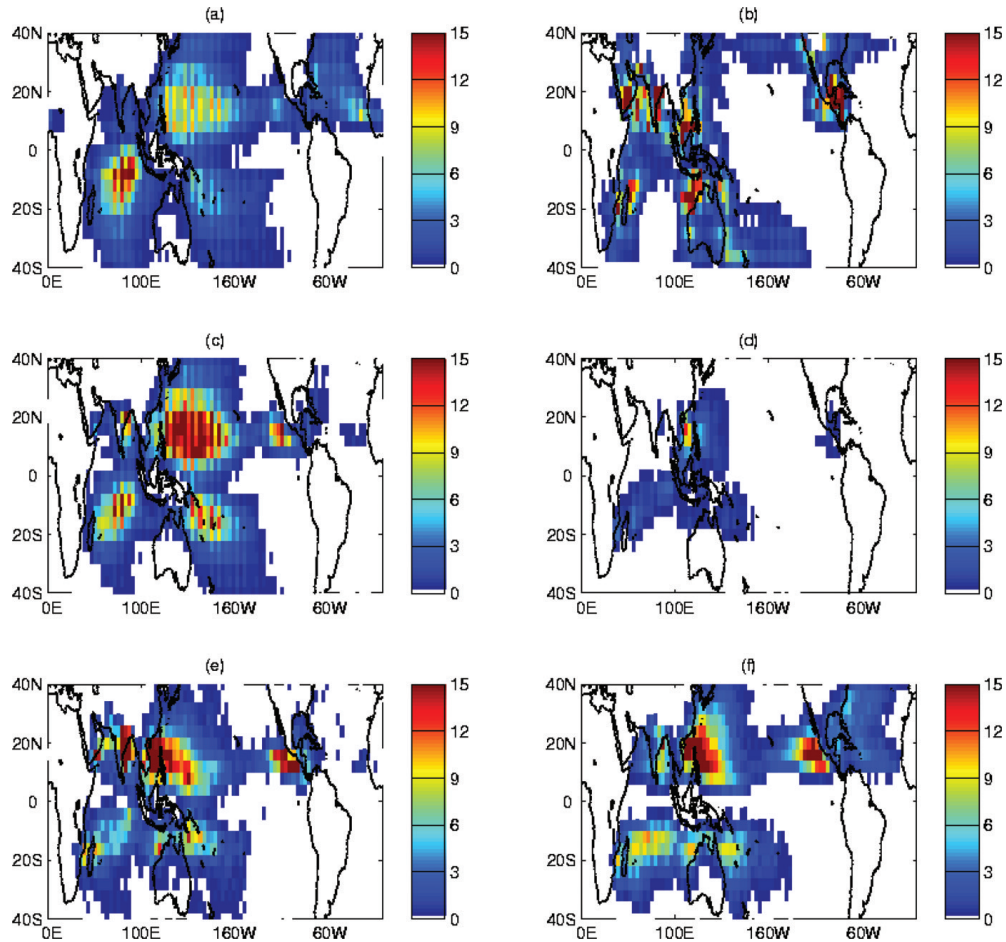
we used a relaxed threshold when tracking the storms in order to avoid this problem (Camargo and Zebiak, 2002). A similar tracking methodology was used in Chauvin et al. (2006).

Another important issue when defining model TCs is the thresholds used in their definition. This is discussed in Walsh et al. (2007), where suggested thresholds depend on model resolution. Here, we used model and basin dependent thresholds to define our storms (Camargo and Zebiak, 2002). In McDonald et al. (2005) fixed thresholds were used (independent of resolution), leading to fewer model tropical storms in the lower resolution integrations. This could be expected, as in lower resolution the model storms reach lower intensities.

Comparing Figs. 1 and 5, one notices that differences in GP climatology between one model and another are not necessarily consistent with differences in the track density between the same two models. For instance, while the GP climatology of the ECHAM3 (Fig. 1a) has the lowest values of all models, the same is not true of its track density (Fig. 5a). The NSIPP model has one of the highest values of the GP in the North Atlantic (Fig. 1d), but very low TC activity in that region (Fig. 5d). Clearly, model-to-model differences in the simulated GP in a specific region, or even for the global mean, need not have any consistent relationship to the corresponding differences in TC activity. This suggests that the differences in TC number are due to differences in the dynamics of the simulated storms themselves, rather than in the simulated large-scale environment for genesis as represented by the GP.

Let us compare in more detail the GP and the number of TCs, by comparing the annual cycle of both quantities in the western North Pacific (Fig. 6) and the North Atlantic (Fig. 7). While in some cases there is a good match in the phasing of the annual cycle of TC activity and the mean GP (e.g. Figs. 6a, 6c and 7a), in other cases the match is marginal or poor (e.g. Figs. $6 b, 6 d, 7 b$ and $7 \mathrm{~d}$ ). Thus, in some cases the peak of the model TC activity does not occur when the model GP peaks, while in reanalysis the coincidence of the two quantities is close (see Figs. $6 \mathrm{f}$ and 7f). The GP was developed by fitting the reanalysis data to describe the seasonal cycle and the spatial variation of the genesis location, so agreement between the seasonal cycles of GP and the NTC globally is essentially guaranteed by construction of the GP. The same is not true on the scale of individual basins, since information on individual basins was not used in the development of the GP.

The relationship between the GP and the number of TCs generated by a given model is further examined by looking at the scatterplot of the models' mean GP and number of TCs (NTC) in the western North Pacific for the period of July to October for all years and ensemble members, shown in Fig. 8a. Each point represents a single year and single ensemble member. The clustering of the different models in different parts of the plot indicates that there is not a consistent relationship, across models, between a model's western North Pacific mean GP and its western North Pacific mean NTC. Further, within any given model, there is not an immediately evident positive relationship between the GP and NTC from one year or ensemble member to another. However, Fig. $8 \mathrm{~b}$ shows a weak positive relationship between the mean GP and NTC in the eastern part of the western North Pacific. As discussed above in the context of Table 2, interannual variability in the western North Pacific (most of which is related to ENSO) is largely manifest as a shift in genesis location, with substantial GP anomalies in subbasins which largely cancel in the integral over the basin as a whole.

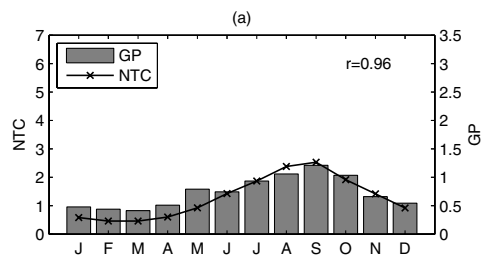

(c)

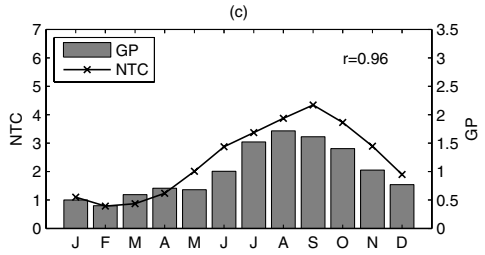

(e)

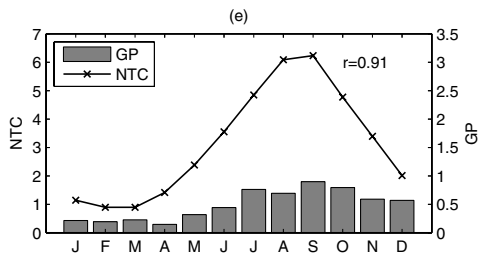

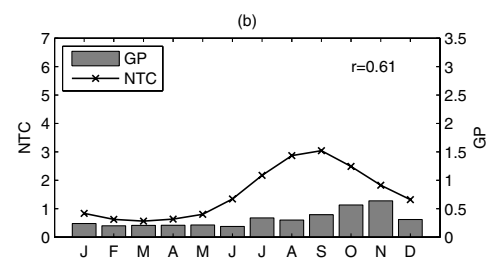

(d)

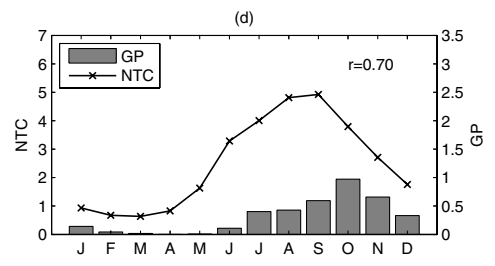

(f)

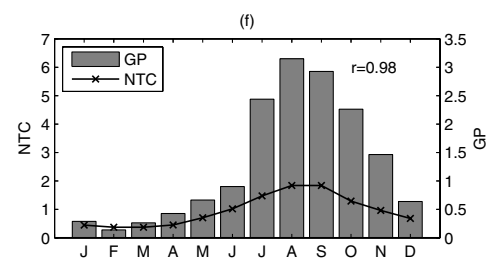

Fig. 6. Annual cycle of genesis potential (GP) index (bars - right scale), and number of tropical cyclones (NTC) in the western North Pacific for the period 1961-2000 in models: ECHAM3 (a), CCM3 (b), ECHAM4 (c), NSIPP (d), ECHAM5 (for 1978-1999, resolution T42) (e), NCEP reanalysis GP and observed NTC (f). 
Fig. 7. Annual cycle of genesis potential index (GP) (bars - right scale), and number of tropical cyclones (NTC) in the North Atlantic for the period 1961-2000 in models: ECHAM3 (a), CCM3 (b), ECHAM4 (c), NSIPP (d), ECHAM5 (for 1978-1999, resolution T42) (e), NCEP reanalysis GP and observed NTC (f).
Fig. 8. Scatter plot of number of model tropical cyclones (NTC) and genesis potential index (GP) in the western North Pacific (a) and the eastern part of the western North Pacific (b) in the period July to October.

Next we examine the interannual correlations of the mean model GP during peak season and the number of model TCs for the same season in individual basins and subbasins (as defined in Table 2). The correlations between mean GP and number of model TCs per basin during the peak season are given in Table 5 . These correlations are strongly dependent on basin and model. While the correlation in the Atlantic for ECHAM4 model is high and significant (0.77), in the western North Pacific it is much smaller, for the reason discussed above. While the total western north Pacific TC activity level does not have marked
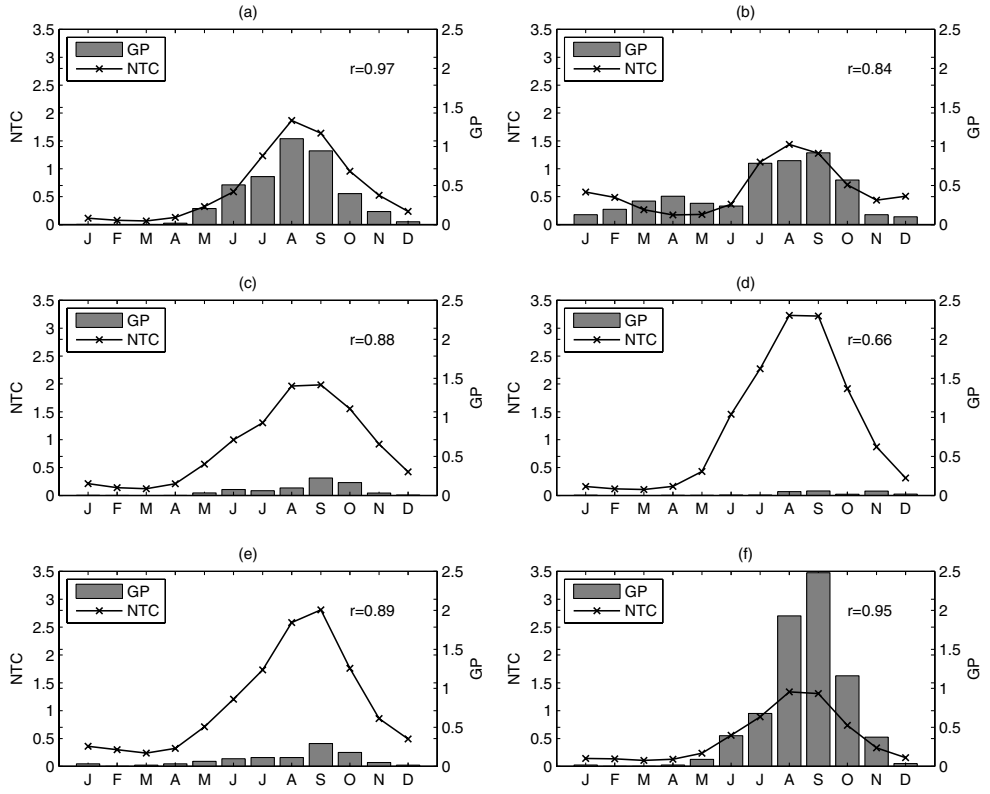

(a)

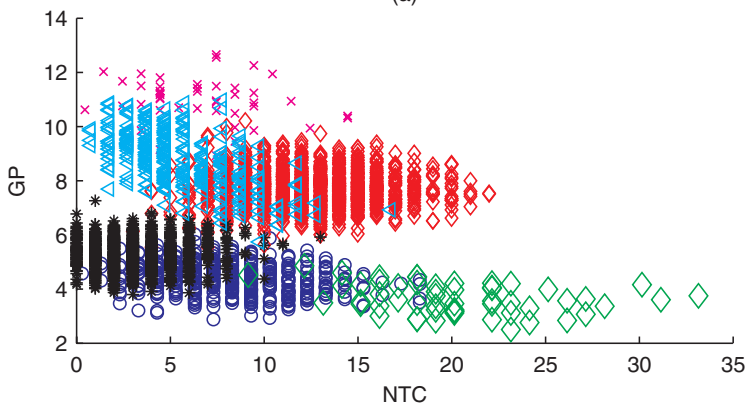

(b)
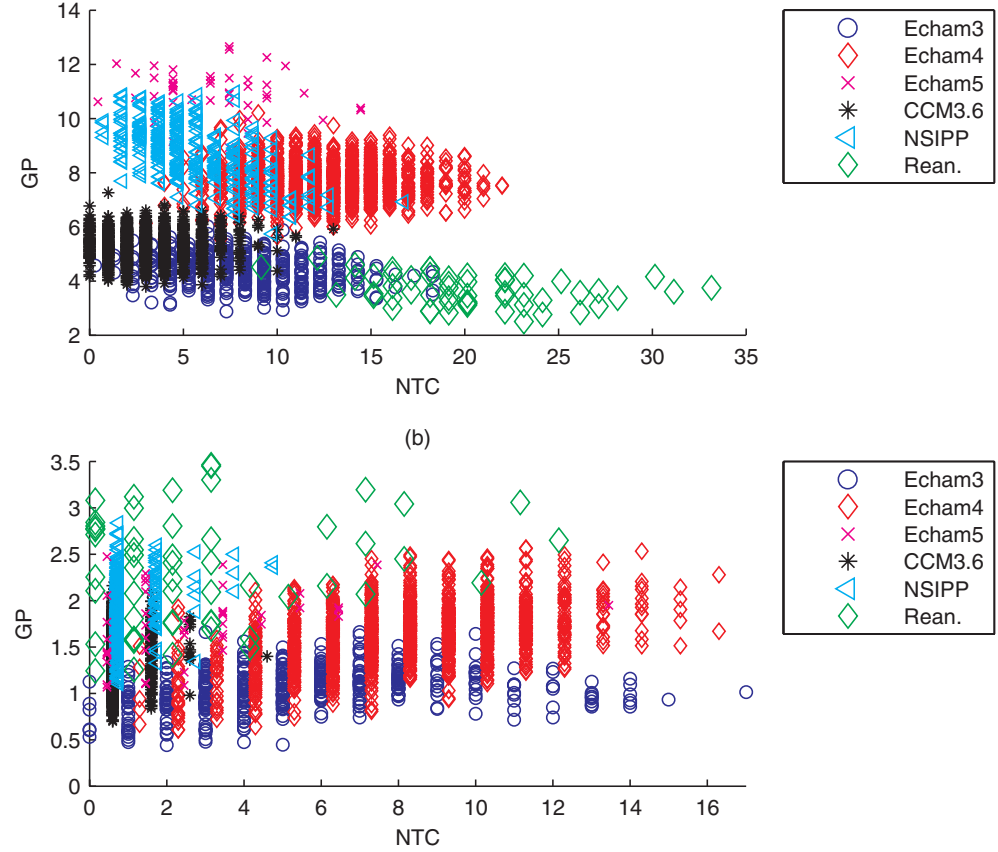

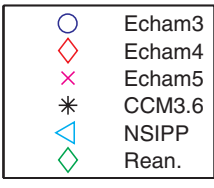

interannual variability, an ENSO influence is clearly reflected in the subbasin activity levels (e.g. Wang and Chan, 2002), the southeastern part having enhanced TC activity during El Niño. The ENSO GP anomalies in the western North Pacific have a corresponding dipole, with opposing anomalies in the subregions defined by this shift (Camargo et al., 2007a). Accordingly, when the basin is divided into eastern and western subbasins, the interannual correlation between the models' observed mean GP and the observed number of TCs increases dramatically (Table 6). Somewhat larger correlations for appropriately 
Table 5. Correlation between the model mean GP, per basin (as defined in Table 2), and the model number of tropical cyclones (NTC) in each basin's peak TC season for the period 1950-2000 (ECHAM3), 1950-2004 (ECHAM4 and NSIPP), 1978-1999 (ECHAM5resolution T42) and 1950-2001 (CCM). Bold entries indicate correlation values that have significance at the $95 \%$ confidence level Entries with an asterisk $(*)$ have zero model NTC counts for at least half of the years in the sample

\begin{tabular}{lccccccc}
\hline Model & SI & AUS & SP & NI & WNP & ENP & ATL \\
\hline CCM & $\mathbf{0 . 4 0}$ & $\mathbf{0 . 2 8}$ & $\mathbf{0 . 4 8}$ & $\mathbf{0 . 7 1}$ & 0.09 & -0.20 & -0.01 \\
NSIPP & $\mathbf{0 . 5 5}$ & $\mathbf{0 . 4 9}$ & 0.26 & $0.16 *$ & -0.76 & -0.33 & -0.05 \\
ECHAM3 & $\mathbf{0 . 4 0}$ & -0.45 & -0.27 & 0.22 & -0.21 & $\mathbf{0 . 6 6}$ & $\mathbf{0 . 4 1}$ \\
ECHAM4 & $\mathbf{0 . 4 7}$ & 0.12 & -0.28 & 0.21 & $\mathbf{0 . 4 0}$ & $\mathbf{0 . 5 9}$ & $\mathbf{0 . 7 7}$ \\
ECHAM5 & 0.11 & -0.18 & -0.15 & 0.36 & 0.08 & 0.13 & 0.15 \\
\hline
\end{tabular}

Table 6. Correlation between the model mean GP per subbasin (as defined in Table 2), and the total model NTC in each basin's peak TC season in the period 1950-2000 (ECHAM3), 1950-2004 (ECHAM4 and NSIPP), 1978-1999 (ECHAM5-resolution T42) and 1950-2001 (CCM). Bold entries indicate correlation values that have significance at the $95 \%$ confidence level. Entries with an asterisk $(*)$ have zero model NTC counts for at least half of the years in the sample

\begin{tabular}{lcccccc}
\hline Model & SI S & SI N & AUS S & AUS N & SP S & SP N \\
\hline CCM & $\mathbf{0 . 5 6}$ & -0.10 & $\mathbf{0 . 3 6}$ & -0.30 & $\mathbf{0 . 5 2}$ & $0.06 *$ \\
NSIPP & $\mathbf{0 . 5 8}$ & $\mathbf{0 . 3 4}$ & $\mathbf{0 . 5 4}$ & 0.18 & 0.18 & $\mathbf{0 . 7 9} *$ \\
ECHAM3 & 0.27 & $\mathbf{0 . 5 3}$ & 0.11 & $\mathbf{0 . 6 7}$ & -0.11 & $\mathbf{0 . 9 2} *$ \\
ECHAM4 & $\mathbf{0 . 4 6}$ & $\mathbf{0 . 6 1}$ & $\mathbf{0 . 6 9}$ & $\mathbf{0 . 3 2}$ & $\mathbf{0 . 4 2}$ & $\mathbf{0 . 9 5}$ \\
ECHAM5 & -0.05 & 0.32 & $\mathbf{0 . 4 7}$ & 0.39 & $0.32 *$ & $\mathbf{0 . 9 2} *$ \\
& & & & & & \\
Model & NI W & NI E & WNP W & WNP E & ATL W & ATL E \\
& & & & & & \\
CCM & $\mathbf{0 . 6 3}$ & $\mathbf{0 . 7 4}$ & $\mathbf{0 . 3 0}$ & 0.19 & 0.26 & $0.01 *$ \\
NSIPP & $-0.32 *$ & $0.31 *$ & -0.81 & $\mathbf{0 . 5 5}$ & 0.17 & $0.00 *$ \\
ECHAM3 & $0.06 *$ & $\mathbf{0 . 4 0}$ & -0.01 & $\mathbf{0 . 3 3}$ & $\mathbf{0 . 6 0}$ & $\mathbf{0 . 8 4}$ \\
ECHAM4 & 0.16 & 0.22 & $\mathbf{0 . 6 1}$ & $\mathbf{0 . 8 4}$ & $\mathbf{0 . 8 4}$ & $\mathbf{0 . 4 4}$ \\
ECHAM5 & $-0.02 *$ & $0.39 *$ & -0.07 & $\mathbf{0 . 4 6}$ & 0.25 & $0.09 *$ \\
\hline
\end{tabular}

divided subbasins are also found in most Southern Hemisphere basins. Note that because the ECHAM5 model has only two ensemble members (Table 1) its correlations are expected to be somewhat diminished compared with those of larger ensembles.

It has been shown in previous studies that the skill of the models in simulating TC activity on a seasonal to interannual timescale is model and basin dependent (Camargo et al., 2005). In some of the basins in which the models were found to have significant skill for the number of TCs, such as the eastern North Pacific and the Atlantic (see tables 6 and 7 in Camargo et al., 2005), correlations between the GP and the number of TCs are positive and significant in the present study. In models that have problems producing TCs in some basins, with a mean number near zero (e.g. NSIPP in the Atlantic; see table 2 in Camargo
Table 7. Correlation between the model mean GP, per basin (as defined in Table 2), and the total NTC per basin in the observations for different basins in their peak TC seasons. Due to issues in data quality in the observations, the correlation was calculated for the period of 1971 onwards: 1971-2000 (ECHAM3), 1971-2004 (NCEP reanalysis, ECHAM4 and NSIPP), 1978-1999 (ECHAM5) and 1971-2001 (CCM). Bold entries indicate correlation values that have significance at the $95 \%$ confidence level. Entries with an asterisk (*) have zero model NTC counts for at least half of the years in the sample

\begin{tabular}{lcccccccc}
\hline Model & Resol & SI & AUS & SP & NI & WNP & ENP & ATL \\
\hline reanalysis & $2.5^{\circ}$ & 0.23 & 0.25 & $\mathbf{0 . 3 8}$ & 0.06 & 0.13 & 0.22 & $\mathbf{0 . 6 0}$ \\
CCM & T42 & -0.29 & $\mathbf{0 . 4 6}$ & -0.28 & -0.10 & 0.30 & 0.30 & $\mathbf{0 . 4 6}$ \\
NSIPP & $2.5^{\circ}$ & -0.09 & 0.31 & -0.09 & 0.27 & 0.10 & 0.29 & $\mathbf{0 . 5 0}$ \\
ECHAM3 & T42 & -0.01 & $\mathbf{0 . 5 0}$ & -0.29 & 0.10 & -0.20 & 0.17 & 0.00 \\
ECHAM4 & T42 & 0.09 & $\mathbf{0 . 3 7}$ & -0.27 & $\mathbf{0 . 3 5}$ & 0.17 & 0.28 & $\mathbf{0 . 3 6}$ \\
ECHAM5 & T42 & -0.02 & 0.29 & -0.09 & -0.01 & 0.21 & $\mathbf{0 . 5 6}$ & $\mathbf{0 . 5 3}$ \\
ECHAM5 & T63 & -0.06 & 0.39 & -0.05 & -0.05 & 0.21 & $\mathbf{0 . 5 4}$ & 0.33 \\
ECHAM5 & T85 & -0.09 & 0.20 & -0.03 & 0.01 & 0.28 & $\mathbf{0 . 4 7}$ & $\mathbf{0 . 4 7}$ \\
ECHAM5 & T106 & -0.01 & 0.30 & -0.13 & 0.11 & -0.04 & $\mathbf{0 . 6 2}$ & 0.27 \\
ECHAM5 & T159 & 0.05 & 0.38 & 0.30 & 0.01 & 0.21 & $\mathbf{0 . 5 4}$ & $\mathbf{0 . 4 3}$ \\
\hline
\end{tabular}

et al., 2005), the relationship of the GP with the number of TCs is less meaningful, and even a significant correlation should be considered tentatively. Hence, in Table 6 an asterisk on a correlation coefficient indicates that the number of model TCs is zero for at least half of the years in the sample.

It is also of interest whether the seasonal GP in the models can be used as a predictor of seasonal TC activity in observations. To evaluate that, we calculate the correlation of the model mean seasonal GP with the observed number of TCs in the peak season for different regions (as defined in Table 2), shown in Tables 7 and 8 for whole basins and their subregions, respectively. Again, the skill of the models is basin and model dependent, and in many basins higher skill is obtained in their subregions. In some models, the correlation between model GP and observed TC number is larger than that between model GP and TC number in the same model. The models have skill in the Australian, South Pacific, western and eastern North Pacific and Atlantic basins (sometimes in just one of the subbasins). This implies that the GP could be used to complement the dynamical forecasts in regions where tracking models' TC activity explicitly does not lead to significant skill, as in the case of the Bay of Bengal (in eastern North Indian Ocean) using the ECHAM4 model.

\section{Influence of spatial resolution on the genesis potential index}

It is well known that increasing horizontal resolution tends to improve a model's ability to reproduce TCs (Bengtsson et al., 1995). Given the strong control on TC dynamics known to be exerted by horizontal resolution, it may be natural to assume that it is this control on simulated TC dynamics that makes the 
Table 8. Correlation between the model mean GP per subbasin (as defined in Table 2), and the total NTC per subbasin in the observations for in their peak TC seasons. Due to issues in data quality in the observations, the correlation was calculated for the period of 1971 onwards: 1971-2000 (ECHAM3), 1971-2004 (NCEP reanalysis, ECHAM4 and NSIPP), 1978-1999 (ECHAM5-resolution T42) and 1971-2001 (CCM). Bold entries indicate correlation values that have significance at the $95 \%$ confidence level. Entries with an asterisk (*) have zero model NTC counts for at least half of the years in the sample

\begin{tabular}{lcccccc}
\hline Model & SI S & SI N & AUS S & AUS N & SP S & SP N \\
\hline reanalysis & $\mathbf{0 . 4 3}$ & 0.07 & $\mathbf{0 . 3 7}$ & 0.16 & 0.19 & $\mathbf{0 . 7 7}$ \\
CCM & 0.02 & -0.03 & $\mathbf{0 . 5 7}$ & 0.30 & -0.09 & $\mathbf{0 . 6 6} *$ \\
NSIPP & -0.19 & 0.26 & $\mathbf{0 . 5 0}$ & 0.24 & -0.02 & $\mathbf{0 . 7 0} *$ \\
ECHAM3 & 0.07 & 0.12 & $\mathbf{0 . 6 9}$ & 0.17 & -0.18 & $\mathbf{0 . 6 4} *$ \\
ECHAM4 & 0.19 & 0.19 & $\mathbf{0 . 5 3}$ & 0.25 & -0.09 & $\mathbf{0 . 7 4} *$ \\
ECHAM5 & -0.03 & -0.08 & $\mathbf{0 . 4 8}$ & 0.07 & -0.06 & $\mathbf{0 . 7 7} *$ \\
& & & & & & \\
Model & NI W & NI E & WNP W & WNP E & ATL W & ATL E \\
& & & & & & \\
reanalysis & 0.18 & 0.12 & 0.31 & $\mathbf{0 . 6 7}$ & $\mathbf{0 . 6 7}$ & 0.11 \\
CCM & -0.14 & -0.04 & -0.01 & $\mathbf{0 . 4 7}$ & $\mathbf{0 . 6 0}$ & 0.10 \\
NSIPP & -0.21 & $\mathbf{0 . 3 8}$ & 0.26 & $\mathbf{0 . 7 3}$ & $\mathbf{0 . 5 2}$ & 0.21 \\
ECHAM3 & -0.02 & 0.12 & 0.34 & 0.18 & 0.18 & -0.23 \\
ECHAM4 & 0.05 & $\mathbf{0 . 3 9}$ & $\mathbf{0 . 4 3}$ & $\mathbf{0 . 4 9}$ & $\mathbf{0 . 4 9}$ & 0.04 \\
ECHAM5 & 0.13 & 0.04 & $\mathbf{0 . 5 1}$ & $\mathbf{0 . 5 5}$ & $\mathbf{0 . 5 8}$ & 0.06 \\
\hline
\end{tabular}

statistics of TC activity so resolution-dependent. Here, while we do not evaluate this assumption, we explore whether some of this resolution dependence may also be due to changes in the simulated environment, as represented by the simulated GP.

The GP was calculated for the ECHAM5 model at five different horizontal resolutions: T42, T63, T85, T106, and T159, as described in Table 1. In all cases the model was forced with observed SSTs for the period 1978-1999. For T42, T63, T85 and T106, there are two ensemble members, one with 19 levels and one with 31 levels. In the case of T63, there are three additional ensemble members with 19 levels, while for T159 there is only one ensemble member with 31 levels. The cyclone (tropical and extratropical) activity of the ECHAM5 model was examined in Bengtsson et al. (2006), who tracked the cyclones using the method described in Hodges (1994). Here, we showed the TC activity of the ECHAM5 with T42 horizontal resolution, computed using the method of Camargo and Zebiak (2002), in Figs. 5-7.

The annual cycle of GP in the ECHAM5 simulations is shown for four basins in Fig. 9, as a function of the horizontal resolution. In all cases, the minimum values of the mean GP at the peak season occurs for the lowest resolution (T42). The GP tends to increase as resolution increases. The largest increases occur when resolution is increased from T42 to T63, and the largest values occur at T159; variations for resolutions between those values are relatively small and non-monotonic as a function of resolution, though in some cases there is an appreciable increase going from T106 to T159.

These results imply that when the horizontal resolution of the model is increased, not only is there an improvement in the dynamics of the simulated TC-like disturbances, but the environmental conditions also become more conducive to generation of TCs, at least for the ECHAM5. Even if this result holds in other models, it is not immediately obvious that the environmental changes are for the better in terms of their impact on cyclone genesis and life cycle, since different models have different relationships between the simulated GP and NTC. The lower portion of Table 7 reveals no systematic increase in correlation between model GP and observed NTC in any of the basins, as wholes, when increasing the resolution in the ECHAM5 model. (A more sensitive examination might apply this analysis to correlations for the subbasins.) However, for basins in which the region conducive to genesis is relatively small in spatial extent, and which have negative biases in some models, such as the North Atlantic and eastern North Pacific, it is reasonable to speculate that increasing horizontal resolution may lead to improvement in the simulated TC climatology, due to both its effect on storm dynamics and on the environment.

\section{Discussion and conclusions}

The genesis potential index (GP) has been used to predict the potential for tropical cyclogenesis on the basis of several largescale environmental variables known to contribute to tropical cyclone (TC) genesis. Here we examine the GP, and its relationship with TC number, in several atmospheric climate models that are forced with historical observed SST as the lower boundary condition over a multidecadal hindcast period. These GP versus TC number relationships in the models are compared with those found in reanalysis in several ocean basins during their peak TC seasons. The motivation is to explore to what extent today's models are able to reproduce the spatial and temporal variations of the GP index computed from the reanalysis data, and to identify consequent effects on the models' abilities to predict the interannual or interdecadal variability, or a climate change-related trend, in TC activity. Because a lack of adequate horizontal resolution is a known impediment to realistic reproduction of TCs in climate models, a range of spectral resolutions (from T42 to $\mathrm{T} 159$ ) in one of the models is used to investigate effects on the model GP.

The models are found to reproduce quite well the reanalysisobserved phasing of the annual cycle of GP in a given region. However, most of the models have a considerably higher GP, overall, than that observed. An analysis of the fields of relative difference between model and reanalysis, for each factor, by basin and model, indicates that the relative humidity contributes to the models' inflated GP more than any other factor. This is particularly true for ECHAM4, ECHAM5 and NSIPP, whose GP values are higher than the observed GP by the greatest per- 

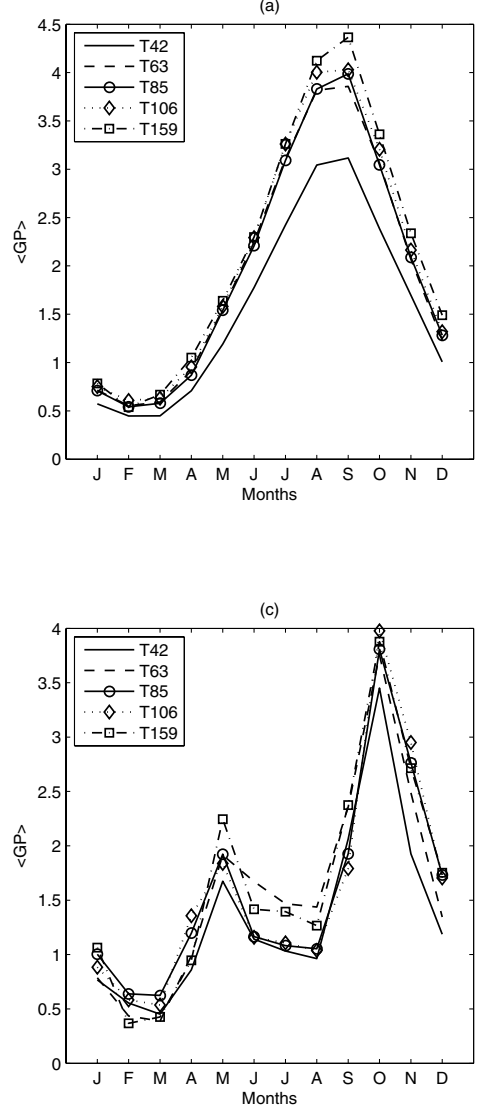

(b)

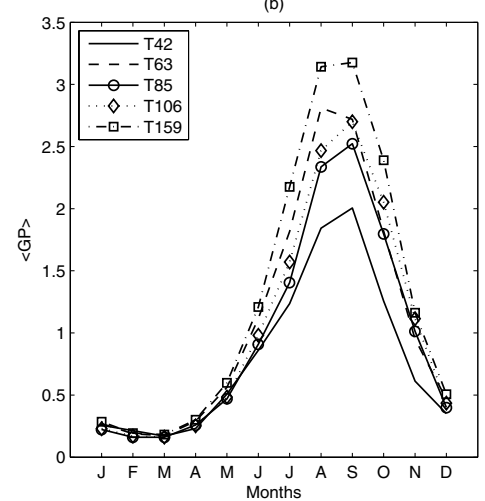

(d)

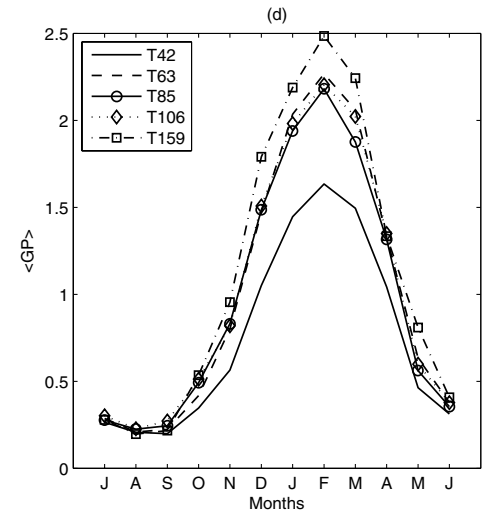

Fig. 9. Genesis potential index in the period 1978-1999 for the ECHAM5 model for 5 different horizontal resolutions (T42, T63, T85, T106 and T159) in the (a) Western North Pacific, (b) North Atlantic, (c) North Indian and (d) South Indian basins. centages. A caveat that should be kept in mind is that the relative humidity in the reanalysis is itself largely a product of the assimilating numerical model, rather than of the input observations, and may not represent reality perfectly.

The models have their own distinct, and widely differing, relationships between mean GP and mean number of TCs. For example, in the Northern Hemisphere the ECHAM4 and NSIPP models have GP index within about $15 \%$ of one another for the June-November period, but ECHAM4 has roughly four times the number of TCs of NSIPP. This strongly suggests that the large variations in the TC climatologies of the models are controlled more by variations in the dynamics of the model storms themselves than by variations in the simulated environments for genesis, as represented by the GP.

The interannual correlation of GP and number of TCs differs significantly from one model to another, either falling short of, equaling, or in some cases exceeding that found in the reanalysis for a given region during its active TC season. In some basins, where year-to-year variations in TC behaviour involve mainly a shift in the location of TC genesis and track location within the basin rather than total basin-wide activity (e.g. in the west north Pacific in response to ENSO), the basin-wide average GP and TC number are not expected to meaningfully reflect yearto-year changes in the environmental variables. In the western
North Pacific, such locational signals are better reflected in the indices, and their interannual correlation becomes significant, when the basin is subdivided into western and eastern portions.

Experiments using different horizontal resolutions of the ECHAM5 model indicate that as horizontal resolution is increased in steps from T42 to T159, model GP index progressively increases by roughly $15-50 \%$, depending on basin and season. Most of this increase is realized in stepping from T42 to T63, with only small further progressive increases up to T159. While a general increase in the correlation between model GP and observed cyclone number was not achieved in whole ocean basins, the increases in GP found when increasing the horizontal resolution implies a more favorable large-scale environment for TC genesis for higher resolution models, and, one would hope, greater responsiveness in terms of TC number. This should be investigated in more detail, by examining the model TC activity in the high-resolution simulations and comparing with the GP index in those simulations. Such expectations are based on McDonald et al. (2005), who noticed that there is more consistency between the model TC activity and genesis indices using a higher horizontal resolution. Furthermore, Chauvin et al. (2006) showed that the comparison between model genesis density and a genesis index using a high-resolution model gives confidence in using genesis indices in low-resolution simulations. 
The GP index can have various possible applications in examining the TC activity in models. For instance, one can examine how the GP index is modified in global warming simulations such as the IPCC runs, as in the study of McDonald et al. (2005). Another possible use is as a diagnostic of the response of the models' TC activity to different climate phenomena, such as ENSO, as was done for the reanalysis in Camargo et al. (2007a). Another possible application is to use the GP to produce dynamical seasonal forecasts of tropical cyclone activity.

\section{Acknowledgments}

The authors would like to thank the Max-Planck Institute for Meteorology (MPI) for making their versions of the ECHAM model accessible to IRI. We thank Dr. Max Suarez (NSIPP), Dr. Erich Roeckner (MPI), Prof. Lennart Bengtsson (University of Reading) for making the NSIPP and the ECHAM5 model data available to us; and Hannes Thiemann (German High Performance Computing Centre for Climate and Earth System ResearchDKRZ) for his support in the ECHAM5 data transfer. We are indebted to Dr. David DeWitt (IRI) for performing the IRI model integrations with support from Dr. Xiaofeng Gong. We thank Dr. Benno Blumenthal for the IRI Data Library. This paper is funded in part by a grant/cooperative agreement from the National Oceanic and Atmospheric Administration, NA050AR4311004. The views expressed herein are those of the authors and do not necessarily reflect the views of NOAA or any of its subagencies. AHS acknowledges support from NSF grant ATM-05-42736.

\section{Appendix A: Potential Intensity}

The definition of potential intensity is based on that given by Emanuel (1995) as modified by Bister and Emanuel (1998). Details of the calculation may be found in Bister and Emanuela (2002a). The definition is also discussed in http://wind.mit.edu/ emanuel/pcmin/pclat/pclat.html. A FORTRAN subroutine to calculate the potential intensity is available at http://wind.mit.edu/ emanuel/home.html. Monthly mean values may be found at http://wind.mit.edu/ emanuel/pcmin/ climo.html. Here we present a very brief overview of Bister and Emanuel (2002a). The formula they use is

$$
V_{\mathrm{pot}}^{2}=\frac{C_{k}}{C_{D}} \frac{T_{s}}{T_{0}}\left(\mathrm{CAPE}^{*}-\mathrm{CAPE}^{b}\right)
$$

where $C_{k}$ is the exchange coefficient for enthalpy, $C_{D}$ is the drag coefficient, $T_{s}$ is the sea surface temperature, and $T_{0}$ is the mean outflow temperature. The convective available potential energy (CAPE) is the vertical integral of parcel buoyancy, which is a function of parcel temperature, pressure, and specific humidity, as well as the vertical profile of virtual temperature. The quantity CAPE* $^{*}$ is the value of CAPE for an air parcel at the radius of maximum winds which has first been saturated at the sea surface temperature and pressure, while $\mathrm{CAPE}^{b}$ refers to the value of CAPE for ambient boundary layer air but with its pressure reduced (isothermally) to its value of at the radius of maximum wind. Thus the variables used to calculate the potential intensity at each grid point are the sea surface temperature and pressure and vertical profiles of temperature and specific humidity.

\section{References}

AMIP II (Atmospheric Model Intercomparison Project II), 2007. AMIP II Sea Surface Temperature and Sea Ice Concentration Observations. Available on line at http://www-pcmdi.llnl.gov/ amip/AMIP2EXPDSN/BCSOBS/amip2bcs.htm.

Anthes, R., Corell, R., Holland, G., Hurrell, J., MacCracken, M., and co-authors. 2006. Hurricanes and global warming — potential linkages and consequences. Bull. Amer. Meteor. Soc. 87, 623-628.

Bengtsson, L. 2001. Hurricane threats. Science 293, 440-441.

Bengtsson, L., Böttger, H. and Kanamitsu, M. 1982. Simulation of hurricane-type vortices in a general circulation model. Tellus 34, 440457.

Bengtsson, L., Botzet, M. and Esch, M. 1995. Hurricane-type vortices in a general circulation model. Tellus 47A, 175-196.

Bengtsson, L., Botzet, M. and Esch, M. 1996. Will greenhouse gasinduced warming over the next 50 years lead to higher frequency and greater intensity of hurricanes?. Tellus 48A, 57-73.

Bengtsson, L., Hodges, K. I. and Roeckner, E. 2006. Storm tracks and climate change. J. Climate 19, 3518-3543.

Bister, M. and Emanuel, K. A. 1998. Dissipative heating and hurricane intensity. Meteor. Atm. Phys. 52, 233-240.

Bister, M. and Emanuel, K. A. 2002a. Low frequency variability of tropical cyclone potential intensity, 1 , interannual to interdecadal variability. J. Geophys. Res. 107, 4801, doi:10.1029/2001JD000776.

Bister, M. and Emanuel, K. A. 2002b. Low frequency variability of tropical cyclone potential intensity, 2, climatology for 1982-1995. J. Geophys. Res. 107, 4621, doi:10.1029/2001JD000780.

Broccoli, A. J. and Manabe, S. 1990. Can existing climate models be used to study anthropogenic changes in tropical cyclone climate? Geophys. Rev. Lett. 17, 1917-1920.

Camargo, S. J. and Sobel, A. H. 2004. Formation of tropical storms in an atmospheric general circulation model. Tellus 56A, 56-67.

Camargo, S. J. and Sobel, A. H. 2005. Western North Pacific tropical cyclone intensity and ENSO. J. Climate 18, 2996-3006.

Camargo, S. J. and Zebiak, S. E. 2002. Improving the detection and tracking of tropical storms in atmospheric general circulation models. Wea. Forecasting 17, 1152-1162.

Camargo, S. J., Barnston, A. G. and Zebiak, S. E. 2004. Properties of tropical cyclones in atmospheric general circulation models. IRI Technical Report 04-02, 72 pp. International Research Institute for Climate Prediction, Palisades, NY.

Camargo, S. J., Barnston, A. G. and Zebiak, S. E. 2005. A statistical assessment of tropical cyclones in atmospheric general circulation models. Tellus 57A, 589-604.

Camargo, S. J., Emanuel, K. A. and Sobel, A. H. 2006. Genesis potential index and ENSO in reanalysis and AGCMs. In: Proc. of 27th Conference on Hurricanes and Tropical Meteorology, 15C.2, American Meteorological Society, Monterey, CA.

Camargo, S. J., Emanuel, K. A. and Sobel, A. H. 2007a. Use of a genesis potential index to diagnose ENSO effects on tropical cyclone genesis. 
IRI Technical Report 07-01, 45 pp., International Research Institute for Climate Prediction, Palisades, NY; J. Climate, in press.

Camargo, S. J., Li, H. and Sun, L. 2007b. Feasibility study for downscaling seasonal tropical cyclone activity using the NCEP regional spectral model. Int. J. Clim. 27, 311-325, doi:10.1002/joc.1400 (Online first).

Chan, J. C. L. 2006. Comment on Changes in tropical cyclone number, duration, and intensity in a warming environment. Science 311, 1713.

Chauvin, F., Royer, J.-F. and Déqué, M. 2006. Response of hurricanetype vortices to global warming as simulated by ARPEGE-Climat at high resolution. Clim. Dyn. 27, 377-399, doi:10.1007/s00382-0060135-7.

Druyan, L. M., Lonergan, P. and Eichler, T. 1999. A GCM investigation of global warming impacts relevant to tropical cyclone genesis. Int. J. Climatol. 19, 607-617.

Emanuel, K. 2005a. Increasing destructiveness of tropical cyclones over the past 30 years. Nature 436, 686-688, doi:10.1038/nature03906.

Emanuel, K. 2005b. Emanuel replies. Nature 438, E13, doi:10.1038/nature04427.

Emanuel, K. A. 1986. An air-sea interaction theory for tropical cyclones. Part I: steady-state maintenance. J. Atmos. Sci. 43, 585-604.

Emanuel, K. A. 1995. Sensitivity of tropical cyclones to surface exchange coefficients and a revised steady-state model incorporating eye dynamics. J. Atmos. Sci. 52, 3969-3976.

Emanuel, K. A. and Nolan, D. S. 2004. Tropical cyclone activity and global climate. In: Proc. of 26th Conference on Hurricanes and Tropical Meteorology, pp. 240-241, American Meteorological Society, Miami, FL.

Gray, W. M. 1979. Hurricanes: their formation, structure and likely role in the tropical circulation. In: Meteorology over the Tropical Oceans. pp. 155-218, Roy. Meteor. Soc.

Haarsma, R. J., Mitchell, J. F. B. and Senior, C. A. 1993. Tropical disturbances in a GCM. Clim. Dyn. 8, 247-257.

Hodges, K. I. 1994. A general method for tracking analysis and its application to meteorological data. Mon. Wea. Rev. 122, 2573-2586.

Hoyos, C. D., Agudelo, P. A., Webster, P. J. and Curry, J. A. 2006. Deconvolution of the factors contributing to the increase in global hurricane intensity. 312, 94-97, Science doi:10.1126/science.1123560.

IRI, 2007. IRI (International Research Institute for Climate and Society) Tropical Cyclone Activity Experimental Dynamical Forecasts. available on line at: http://iri.columbia.edu/forecast/tc_fcst.

JTWC, 2007. JTWC (Joint Typhoon Warning Center) best track dataset. available online at https://metoc.npmoc.navy.mil/jtwc/best_tracks/.

JTWC, 2007. JTWC (Joint Typhoon Warning Center) best track dataset. available online at https://metoc.npmoc.navy.mil/jtwc/best_tracks/.

Kalnay, E., Kanamitsu, M., Kistler, R., Collins, W., Deaven, D., and co-authors. 1996. The NCEP/NCAR 40-year reanalysis project. Bull. Amer. Meteor. Soc. 77, 437-441.

Kiehl, J. T., Hack, J. J., Bonan, G. B., Boville, B. A., Williamson, D. L., and co-authors. 1998. The national center for atmospheric research community climate model: Ccm3. J. Climate 11, 1131-1149.

Knutson, T. R. and Tuleya, R. E. 2004. Impact of $\mathrm{CO}_{2}$-induced warming on simulated hurricane intensity and precipitation: sensitivity to choice of climate model and convective parametrization. J. Climate 17, 34773495.

Landman, W. A., Seth, A. and Camargo, S. J. 2005. The effect of regional climate model domain choice on the simulation of tropical cyclone- like vortices in the southwestern indian ocean. J. Climate 18, 12631274.

Landsea, C. W. 2005. Hurricanes and global warming. Nature 438, E1113, doi:10.1038/nature04477.

Manabe, S., Holloway, J. L. and Stone, H. M. 1970. Tropical circulation in a time-integration of a global model of the atmosphere. J. Atmos. Sci. 27, 580-613.

Mann, M. E. and Emanuel, K. A. 2006. Atlantic hurricane trends linked to climate change. $\operatorname{EOS} \mathbf{8 7}, 233,238,241$.

Matsuura, T., Yumoto, M., Iizuka, S. and Kawamura, R. 1999. Typhoon and ENSO simulation using a high-resolution coupled GCM. Geophys. Res. Lett. 26, 1755-1758.

Matsuura, T., Yumoto, M. and lizuka, S. 2003. A mechanism of interdecadal variability of tropical cyclone activity over the western North Pacific. Clim. Dyn. 21, 105-117.

McDonald, R. E., Bleaken, D. G., Cresswell, D. R., Pope, V. D. and Senior, C. A. 2005. Tropical storms: representation and diagnosis in climate models and the impacts of climate change. Clim. Dyn. 25, $19-36$.

Model User Support Group, 1992. Echam3 - atmospheric general circulation model. Tech. Rep. 6, Das Deutshes Klimarechnenzentrum, Hamburg, Germany, 184 pp.

NHC, 2007. NHC (National Hurricane Center) best track dataset. available online at http://www.nhc.noaa.gov.

Nolan, D. S., Rappin, E. D. and Emanuel, K. A. 2006. Could hurricanes form from random convection in a warmer world?. In: Proc. of 27th Conference on Hurricanes and Tropical Meteorology, 1C.8, American Meteorological Society, Monterey, CA.

Oouchi, K., Yoshimura, J., Yoshimura, H., Mizuta, R., Kusunoki, S. and co-authors. 2006. Tropical cyclone climatology in a global-warming climate as simulated in a $20 \mathrm{~km}$-mesh global atmospheric model: Frequency and wind intensity analyses. J. Meteor. Soc. Japan 84, 259-276.

Pielke, R. Jr., Landsea, C., Mayfield, M., Laver, J. and Pasch, R. 2006. Reply to Hurricanes and global warming potential linkages and consequences. Bull. Amer. Meteor. Soc. 87, 628-631.

Pielke, R. A. Jr. 2005. Are there trends in hurricane destruction?. Nature 438, E11, doi:10.1038/04426.

Pielke, R. A. Jr., Landsea, C., Mayfield, M., Laver, J. and Pasch, R. 2005. Hurricanes and global warming. Bull. Amer. Meteor. Soc. 86, 1571-1575.

Reynolds, R. W. and Smith, T. M. 1994. Improved global sea surface temperature analyses using optimum interpolation. J. Climate 7, 929948.

Reynolds, R. W., Rayner, N. A., Smith, T. M., Stokes, D. C. and Wang, W. 2002. An improved in situ and satellite SST analysis for climate. J. Climate 15, 1609-1625.

Roeckner, E., Arpe, K., Bengtsson, L., Christoph, M., Claussen, M., and co-authors. 1996. The atmospheric general circulation model ECHAM-4: Model description and simulation of present-day climate. Tech. Rep. 218, Max-Planck Institute for Meteorology, Hamburg, Germany, 90 pp.

Roeckner, E., Bäuml, G., Bonaventura, L., Brokopf, R., Esch, M. and co-authors. 2003. The atmospheric general circulation model ECHAM5. Part I: Model description. Tech. Rep. 349, MaxPlanck Institute for Meteorology, Hamburg, Germany, 127 pp. 
Royer, J.-F., Chauvin, F., Timbal, B., Araspin, P. and Grimal, D. 1998. A GCM study of the impact of greenhouse gas increase on the frequency of occurrence of tropical cyclone. Climatic Change 38, 307343.

Ryan, B. F., Watterson, I. G. and Evans, J. L. 1992. Tropical cyclone frequencies inferred from Gray's yearly genesis parameter: Validation of GCM tropical climate. Geophys. Res. Lett. 19, 1831-1834.

Suarez, M. J. and Takacs, L. L. 1995. Documentation of the Aries/GEOS dynamical core Version 2. Technical Report Series on Global Modelling and Data Assimilation, NASA Technical Memorandum 104606 Vol. 5, Goddard Space Flight Center, Greenbelt, MD, USA, 58 pp.

Sugi, M., Noda, A. and Sato, N. 2002. Influence of global warming on tropical cyclone climatology: An experiment with the JMA global model. J. Meteor. Soc. Japan 80, 249-272.

Thorncroft, C. and Pytharoulis, I. 2001. A dynamical approach to seasonal prediction of Atlantic tropical cyclone activity. Wea. Forecasting 16, 725-734.

Tsutsui, J. I. and Kasahara, A. 1996. Simulated tropical cyclones using the National Center for Atmospheric Research community climate model. J. Geophys. Res. 101, 15013-15032.

Vitart, F. 2006. Seasonal forecasting of tropical storm frequency using a multi-model ensemble. Q. J. R. Meteorol. Soc. 132, 647-666, doi:10.1256/qj.05.65.

Vitart, F. and Anderson, J. L. 2001. Sensitivity of Atlantic tropical storm frequency to ENSO and interdecadal variability of SSTs in an ensemble of AGCM integrations. J. Climate 14, 533-545.

Vitart, F. Anderson, J. L. and Stern, W. F. 1997. Simulation of interannual variability of tropical storm frequency in an ensemble of GCM integrations. J. Climate 10, 745-760.

Vitart, F., Anderson, J. L. and Stern, W. F. 1999. Impact of large-scale circulation on tropical storm frequency, intensity and location, simulated by an ensemble of GCM integrations. J. Climate 12, 3237-3254.

Vitart, F., Anderson, D. and Stockdale, T. 2003. Seasonal forecasting of tropical cyclone landfall over Mozambique. J. Climate 16, 3932-3945.
Vitart, F. D. and Stockdale, T. N. 2001. Seasonal forecasting of tropical storms using coupled GCM integrations. Mon. Wea. Rev. 129, 25212537.

Walsh, K. 2004. Tropical cyclones and climate change: unresolved issues. Clim. Res. 27, 77-83.

Walsh, K. J., Fiorino, M., Landsea, C. W. and McInnes, K. L. 2007. Objectively determined resolution-dependent threshold criteria for the detection of tropical cyclones in climate models and reanalyses. $J$. Climate, in press.

Walsh, K. J. E. and Ryan, B. F. 2000. Tropical cyclone intensity increase near Australia as a result of climate change. J. Climate 13, 3029-3036.

Walsh, K. J. E., Nguyen, K. C. and McGregor, J. L. 2004. Fine-resolution regional climate model simulations of the impact of climate change on tropical cyclones near Australia. Clim. Dyn. 22, 47-56.

Wang, B. and Chan, J. C. L. 2002. How strong ENSO events affect tropical storm activity over the western North Pacific. J. Climate 15, 1643-1658.

Watterson, I. G., Evans, J. L. and Ryan, B. F. 1995. Seasonal and interannual variability of tropical cyclogenesis: diagnostics from large-scale fields. J. Climate 8, 3052-3066.

Webster, P. J., Holland, G. J., Curry, J. A. and Chang, H.-R. 2005. Changes in tropical cyclone number, duration, and intensity in a warming environment. Science 309, 1844-1846, doi:10.1126/science.1116448.

Wu, G. and Lau, N. C. 1992. A GCM simulation of the relationship between tropical storm formation and ENSO. Mon. Wea. Rev. 120, 958-977.

Yoshimura, J., Sugi, M. and Noda, A. 2006. Influence of greenhouse warming on tropical cyclone frequency. J. Meteor. Soc. Japan 84, 405-428.

Yumoto, M., Matsuura, T. and Iizuka, S. 2003. Interdecadal variability of tropical cyclone frequency over the western North pacific in a highresolution atmosphere-ocean coupled GCM. J. Meteor. Soc. Japan 81, 1069-1086. 